\title{
Use of allogeneic platelet gel in the management of chemotherapy extravasation injuries: a case report
}

\section{Gaetano Di Costanzo' \\ Giovanna Loquercio' \\ Gianpaolo Marcacci² \\ Vincenzo lervolino' \\ Stefano Mori ${ }^{3}$ \\ Arnolfo Petruzziello' \\ Pasquale Barra' \\ Carmela Cacciapuoti ${ }^{\prime}$}

'Transfusion Service, Department of Haematology, National Cancer Institute "G Pascale" Foundation, IRCCS, Naples, Italy; ${ }^{2}$ Hematology-Oncology and Stem Cell Transplantation Unit, National Cancer Institute "G Pascale" Foundation, IRCCS, Naples, Italy; ${ }^{3}$ Department of Surgery, Melanoma - Soft Tissues - Head and Neck - Skin Cancers, National Cancer Institute "G Pascale" Foundation, IRCCS, Naples, Italy
This article was published in the following Dove Press journal:

OncoTargets and Therapy

9 February 2015

Number of times this article has been viewed
Abstract: The allogeneic platelet (PLT) gel offers to be a valid supportive measure in the management of chemotherapy extravasation injuries. We report a case of a 58-year-old patient with multiple myeloma enrolled for high-dose chemotherapy and autologous stem cell transplantation. As pretransplant therapy, the patient received induction therapy with bortezomib, adriblastina, and desametazone. A port was inserted in the vein on the back of the hand. After three cycles, the patient reported rapid development of redness, pain, and necrotic tissue in the left hand, and a diagnosis of extravasation was addressed. The patient presented a raw area on the back of the hand caused by cytotoxic/chemotherapeutic drug leakage because of the malposition of venous access devices. Skin ulcer was debrided, and the wound was reconstructed with a combination of local random rotational flap and abdomen skin graft. Two weeks later, a $20 \%$ skin flap necrosis was observed. In the context of wound healing, topical plasma-rich PLT gel is able to accelerate the regeneration and repair of tissue, so it was set out to assess PLT gel efficacy in this case. The PLT gel was applied topically once every 5 days, for a duration of 60 days on average. There were no adverse reactions observed during the topical therapy. Complete wound healing was observed after 12 PLT-rich plasma applications. No ulcer recurrence was noted in the patient during the follow-up period of 2-19 months.

Keywords: growth factors, platelet gel, chemotherapy, management, extravasation

\section{Introduction}

Extravasation is an important complication in cancer patients under chemotherapy. ${ }^{1-4}$ Currently, chemotherapy extravasation management remains controversial, ${ }^{3}$ and there is no definitive standard procedure to solve the problem. We report the management of a patient with massive skin necrosis after extravasation of bortezomib, adriblastina, and desametazone. In addition to surgical debridement of necrotic tissue and skin grafting, we used platelet (PLT) gel, rich in growth factors (PDGF, EGF, VEGF, and TGB- $\alpha$ and $-\beta$ ) to stimulate healing of skin ulceration and wound closure. ${ }^{5}$

\section{Case report}

A 58-year-old man with multiple myeloma, ${ }^{6}$ Durie-Salmon stage III, ${ }^{7}$ was enrolled for high-dose chemotherapy and autologous stem cell transplantation. As pretransplant therapy, the patient received induction therapy with bortezomib, adriblastina, and desametazone. A port was inserted on the back of the hand. The patient reported rapid development of redness and pain in the left hand, 2 weeks after the completion of the third cycle. The patient presented a raw area on the back of the hand because of leakage of cytotoxic/chemotherapeutic drugs from the malposition of venous access devices. Skin ulcer was debrided, and the wound was reconstructed with local
Correspondence: Giovanna Loquercio Department of Haematology, National Cancer Institute "G Pascale" Foundation, IRCCS, via Mariano Semmola, 80I3I, Napoli, Italy

$\mathrm{Tel}+39815903433$

Fax+39 8I 5453560

Email giovyloquercio@libero.it 


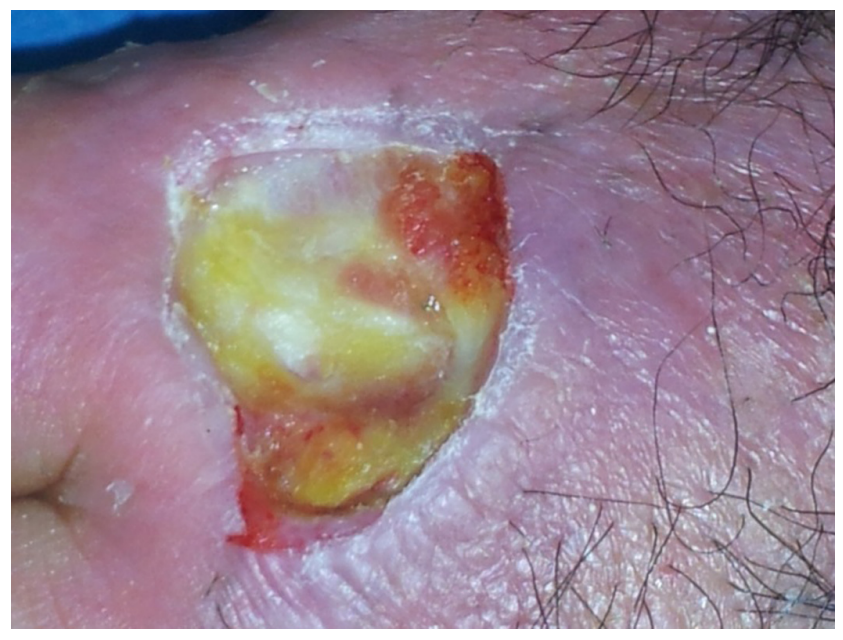

Figure I Skin lesion after surgical debridement of necrotic tissue.

random rotational flap and abdomen skin graft. Two weeks later, a 20\% skin flap necrosis was observed. In the contest of wound healing, numerous studies and clinical findings have demonstrated that topical, nontransfusional plasma-rich PLT gel is able to accelerate the regeneration and repair of the tissue, through the action of the various growth factors within the alpha granules of the PLTs. ${ }^{8-12}$ The PLT gel treatment has been used based on biological and clinical results reported in literature. According to the standard current approach, ${ }^{13}$ the lesion management included the surgical removal of necrotic material and cleansing of margins of the wound bed before PLT gel application (Figure 1). After moist saline dressing, the wound was covered with allogeneic platelet-rich plasma (PRP) and fatty gauze. In our case, a blood component (thrombin) was produced from allogeneic whole blood using a "homemade" system.

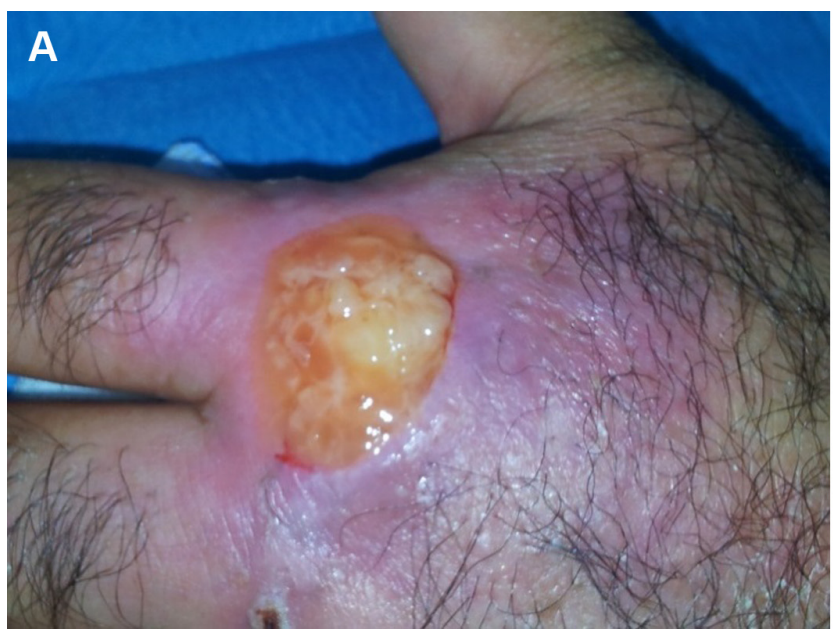

The PLT gel was prepared the day of the treatment. Samples of whole blood (total $40 \mathrm{~mL}$ ) were collected in 10-mL acidcitrate-dextrose vacutainers (Becton Dickinson Labware, Franklin Lakes, NJ, USA) from periodic donors. The whole blood was centrifuged at $180 \mathrm{~g}$ for 10 minutes to obtain concentrated erythrocytes and PRP. PRP were centrifuged again at $1,800 \mathrm{~g}$ for 10 minutes to separate PLT concentrate from PLT-poor plasma.

To activate the PRP homologous and to accelerate the gelling process, thrombin autologous was prepared by adding calcium gluconate to the PLT-poor plasma (ratio $0.2: 1 \mathrm{~mL}$ ). After $15-40$ minutes of incubation at $37^{\circ} \mathrm{C}$, the product was centrifuged at $1,800 \mathrm{~g}$ for $10-15$ minutes. One milliliter of thrombin-containing supernatant and $0.50 \mathrm{~mL}$ of ionized $\mathrm{Ca}^{++}$were added to the previously separated PRP, in a Petri dish (Falcon, Becton Dickinson Labware), and mixed until a gelatinous mixture was obtained (from 2 minutes to 5 minutes). All the procedure has been performed under a laminar-flow hood (Faster Bio48).

The nonhealing ulcer measured $3 \times 4 \mathrm{~cm}$ (Figure 1). Three days after adjusting debridement, the wound was covered with allogeneic PRP (Figure 2A). The PLT gel was applied topically once every 5 days. The healing time was 60 days on average. The wound healed completely after 12 applications (Figure 3). The presence of granulation tissue was observed and recorded by digital photography in the patient after the second application of PLT gel. Figure 1 illustrates the ulcer before the treatment; Figures $2 \mathrm{~B}$ and 3 show the same lesion, respectively, after 20 days and 60 days. No adverse reactions were observed during the topic therapy. No ulcer recurrence during the follow-up period of 2-19 months in the patient was noted.

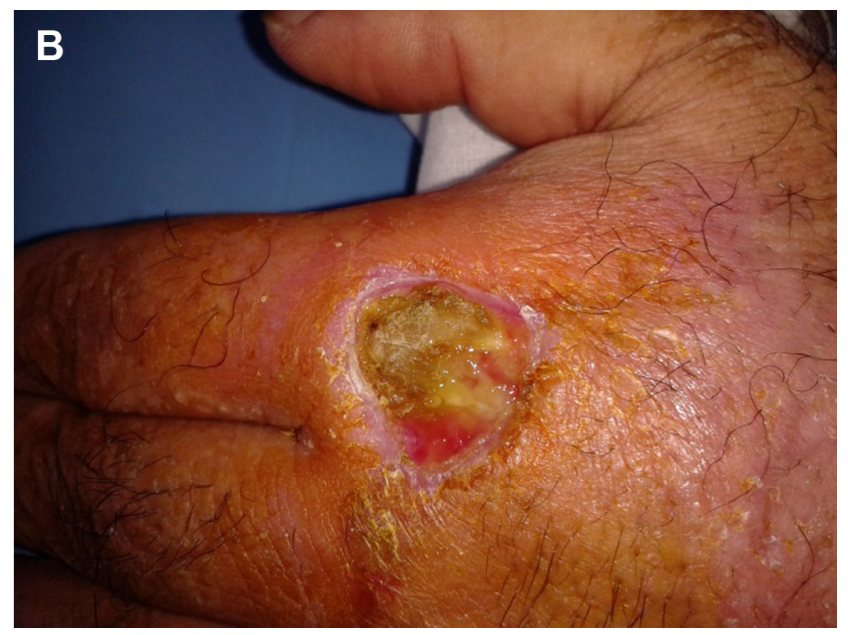

Figure 2 (A) First application of platelet gel. (B) Skin photograph 20 days after the start of therapy. 


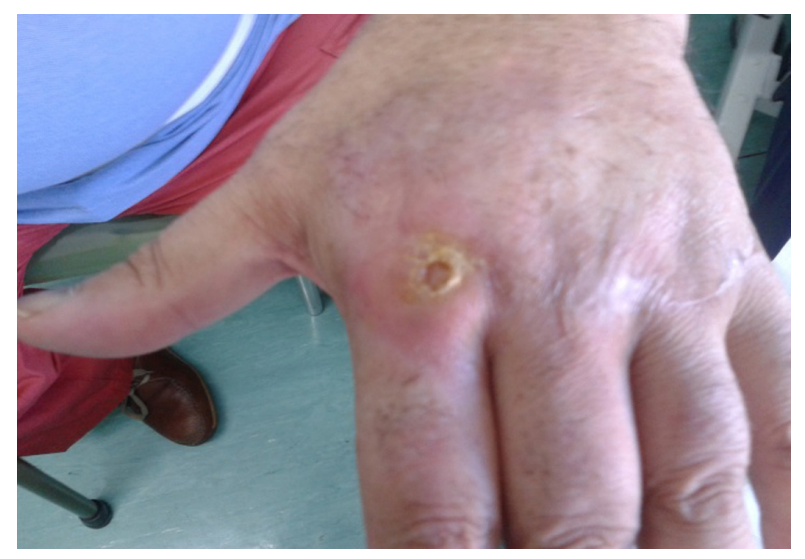

Figure 3 The previous ulceration photograph 60 days posttreatment showing complete closure of the lesion and re-epithelialization tissue with no inflammation.

\section{Discussion}

Accidental extravasation of chemotherapy into surrounding tissue is a frequent event. Indeed, the phenomenon is estimated at a rate of between $0.1 \%$ and $6 \% .^{14-16}$ Treatment of extravasations depends on the quantity extravasated, the delay until therapy is started, and the size of the resulting necrotic injury. Historically, a number of local treatments have been used, such as dimethyl sulfoxide ${ }^{17,18}$ cooling and intralesional injection of corticosteroids ${ }^{19}$ with either no proven benefit or even detrimental effect. However, if the condition is missed, the consequences may be dramatic, with massive necrosis and ensuing tissue destruction. Here we have described the case of a patient with multiple myeloma and severe skin necrosis induced by chemotherapy, who was treated with PLT gel. PLT gel rapidly repaired the ulceration damage, blocked the progression of lesion, reduced the intensity of pain, and restored the patient's ability to move the hand. Greppi et al demonstrated the efficacy of PLT gel to treat recalcitrant ulcers in geriatric and hypomobile patients with chronic skin ulcers unresponsive to previous treatment with advanced medications. ${ }^{13} \mathrm{~A}$ meta-analysis review had revealed PRP as an advanced wound therapy in hard-heal acute and chronic wounds, favored significantly for complete healing. ${ }^{20,21}$ This process was regulated by PLTs, not only for their hemostatic function but also for their ability to repair and regenerate damaged tissues. ${ }^{22-27}$ These mechanisms are regulated by cytokines and growth factors released by activated PLTs. The cytokines and growth factors contained within PLT- $\alpha$ granules act via an endocrine, paracrine, and autocrine mechanism, binding to the tyrosine kinase-activated membrane receptors found on the various tissue effectors, thereby regulating chemotaxis, cell proliferation, angiogenesis, and the synthesis and degradation of extracellular matrix proteins. ${ }^{28-30}$ Although in several clinical studies, topical therapy seems to exhibit no clear adjuvant effect on wound healing, ${ }^{31,32}$ based on our experience we suggest that the use of PLT gel, together with conventional therapies, could be considered as an effective treatment for the management of chemotherapy-induced damage and tissue necrosis in oncologic patients.

\section{Acknowledgment}

We acknowledge the medical assistance of technical and nursing staff: Antonio Mattiello, Vincenza Passante, and Assunta Coppola.

\section{Patient consent}

Patient consent was obtained for this study.

\section{Disclosure}

The authors declare no conflicts of interest in this work.

\section{References}

1. Ener RA, Meglathery SB, Styler M. Exstravasation of systemic hematooncological therapies. Annals Oncol. 2004;15:858-862.

2. Sauerland C, Engelking C, Wickham R, Corbi D. Vesicant extravasation part I: mechanisms, pathogenesis, and nursing care to reduce risk. Oncol Nurs Forum. 2006;33(6):1134-1141.

3. Schulmeister L. Extravasation management: clinical update. Semin Oncol Nurs. 2011;27(1):82-90.

4. Schrijvers DL. Extravasation: a dreaded complication of chemotherapy. Ann Oncol. 2003;14(suppl 3):iii26-iii30.

5. Iervolino V, Di Costanzo G, Azzaro R, et al. Platelet gel in cutaneous radiation dermatitis. Support Care Cancer. 2013;21(1):287-293.

6. Greipp PR, San Miguel J, Durie BG, et al. International staging system for multiple myeloma. J Clin Oncol. 2005;23:3412-3420.

7. Durie BG, Salmon SE. A clinical staging system for multiple myeloma. Correlation of measured myeloma cell mass with presenting clinical features, response to treatment, and survival. Cancer. 1975;36:842-854.

8. Balbo R, Avonto I, Marenchino D, Maddalena L, Menardi G, Peano G. Platelet gel for the treatment of traumatic loss of finger substance. Blood Transfus. 2010;8(4):255-259.

9. Chen TM, Tsai JC, Burnouf T. A novel technique combining platelet gel, skin graft, and fibrin glue for healing recalcitrant lower extremity ulcers. Dermatol Surg. 2010;36(4):453-460.

10. Picardi A, Lanti A, Cudillo L, et al. Rome transplant network. Platelet gel for treatment of mucocutaneous lesions related to graft-versus-host disease after allogeneic hematopoietic stem cell transplant. Transfusion. 2010;50(2):501-506.

11. Sclafani AP, Romo T 3rd, Ukrainsky G, et al. Modulation of wound response and soft tissue ingrowth in synthetic and allogeneic implants with platelet concentrate. Arch Facial Plast Surg. 2005;7(3):163-169.

12. Smrke D, Gubina B, Domanoviç D, Rozman P. Allogeneic platelet gel with autologous cancellous bone graft for the treatment of a large bone defect. Eur Surg Res. 2007;39(3):170-174.

13. Greppi N, Mazzucco L, Galetti G, et al. Treatment of recalcitrant ulcers with allogeneic platelet gel from pooled platelets in aged hypomobile patients. Biologicals. 2011;39:73-80.

14. Schulmeister L, Camp Sorrell D. Chemotherapy extravasation from implanted ports. Oncol Nurs Forum. 2000;27(3):531-538.

15. Schulmeister L. Management vesicant extravasations. Oncologist. 2008; $13: 284-288$. 
16. Yildizeli B, Laçin T, Batirel HF, Yüksel M. Complication and management of long-term central venous access catheters and ports. J Vasc Access. 2004;5(4):174-178.

17. Bertelli G, Gozza A, Forno GB, et al. Topical dimethylsulfoxide for the prevention of soft tissue injury after extravasation of vesicant cytotoxic drugs: a prospective clinical study. J Clin Oncol. 1995;13: 2851-2855.

18. Dorr RT, Alberts DS. Failure of DMSO and vitamin E to prevent doxorubicin skin ulceration in the mouse. Cancer Treat Rep. 1983;67: 499-501.

19. Dorr RT, Alberts DS, Chen HS. The limited role of corticosteroids in ameliorating experimental doxorubicin skin toxicity in the mouse. Cancer Chemother Pharmacol. 1980;5:17-20.

20. Carter MJ, Fylling CP, Parnell LK. Use of platelet rich plasma gel on wound healing: a systematic review and meta-analysis. Eplasty. 2011; 11:e38.

21. de Leon JM, Driver VR, Fylling CP, et al. The clinical relevance of treating chronic wounds with an enhanced near-physiological concentration of platelet-rich plasma gel. Adv Skin Wound Care. 2011;24(8): 357-368.

22. Cooper DM, Yu EZ, Hennessey P, Ko F, Robson MC. Determination of endogenous cytokines in chronic wounds. Ann Surg. 1994;219: 688-691.

23. Everts PA, Brown MC, Hoffmann JJ, et al. Platelet-rich plasma preparation using three devices: implications for platelet activation and platelet growth factor release. Growth Factors. 2006;24:165-171.

24. Frechette JP, Martineau I, Gagnon G. Platelet-rich plasmas: growth factor content and roles in wound healing. $J$ Dent Res. 2005;84:434-439.
25. Mazzucco L, Medici D, Serra M, et al. The use of autologous platelet gel to treat difficult-to-heal wounds: a pilot study. Transfusion. 2004;44: 1013-1018.

26. Okuda K, Kawase T, Momose M, et al. Platelet-rich plasma contains high levels of platelet-derived growth factor and transforming growth factor-beta and modulates the proliferation of periodontally related cells in vitro. J Periodontol. 2003;74:849-857.

27. Tarroni G, Tessarin C, De SL, et al. [Local therapy with platelet-derived growth factors for chronic diabetic ulcers in haemodialysis patients]. G Ital Nefrol. 2002;19:630-633. Italian.

28. Anitua E, Sanchez M, Nurden AT, Nurden P, Orive G, Andia I. New insights into and novel applications for platelet-rich fibrin therapies. Trends Biotechnol. 2006;24:227-234.

29. Borzini P, Mazzucco L. Platelet gels and releasates. Curr Opin Hematol. $2005 ; 12: 473-479$.

30. Verheul HM, Jorna AS, Hoekman K, Broxterman HJ, Gebbink MF, Pinedo HM. Vascular endothelial growth factor-stimulated endothelial cells promote adhesion and activation of platelets. Blood. 2000;96: 4216-4221.

31. Senet P, Bon FX, Benbunan M, et al. Randomized trial and local biological effect of autologous platelets used as adjuvant therapy for chronic venous leg ulcers. J Vasc Surg. 2003;38(6):1342-1348.

32. Stacey MC, Mata SD, Trengove NJ, Mather CA. Randomised double-blind placebo controlled trial of topical autologous platelet lysate in venous ulcer healing. Eur J Vasc Endovasc Surg. 2000;20(3): 296-301.
OncoTargets and Therapy

\section{Publish your work in this journal}

OncoTargets and Therapy is an international, peer-reviewed, open access journal focusing on the pathological basis of all cancers, potential targets for therapy and treatment protocols employed to improve the management of cancer patients. The journal also focuses on the impact of management programs and new therapeutic agents and protocols on

\section{Dovepress}

patient perspectives such as quality of life, adherence and satisfaction The manuscript management system is completely online and includes a very quick and fair peer-review system, which is all easy to use. Visit http://www.dovepress.com/testimonials.php to read real quotes from published authors. 